\title{
Rancang Bangun Sistem Informasi Geografis Monitoring Proyek Hotel Berbasis Web
}

\author{
Leni Fitriani ${ }^{1}$, Titin Rostini ${ }^{2}$ \\ Jurnal Algoritma \\ Sekolah Tinggi Teknologi Garut \\ Jl. Mayor Syamsu No. 1 Jayaraga Garut 44151 Indonesia \\ Email : jurnal@itg.ac.id \\ ${ }^{1}$ leni.fitriani@itg.ac.id \\ 21606111@itg.ac.id
}

\begin{abstract}
Abstrak - Perusahaan Terbatas Sumber Berkat Indonesia bergerak di bidang kontruksi, dalam menjalankan bisnis sering kali mendapat permintaan untuk membangun sebuah proyek di beberapa titik lokasi berjauhan di wilayah yang berbeda. Pada praktiknya karena banyaknya titik lokasi proyek dan saling berjauhan satu sama lain membuat pihak manajemen pusat kesulitan untuk melakukan monitoring, selain itu sering terjadi gesekan antara pengembang dengan masyarakat umum dikarenakan kurangnya komunikasi antara pengembang dengan masyarakat. Oleh karena itu tujuan penelitian ini untuk membangun sebuah sistem yang mampu menampung data pelaporan dari tiap - tiap mandor di setiap lokasi proyek dan menyediakan saluran komunikasi antara masyarakat dengan pimpinan perusahaan melalui fitur keluhan. Metodologi yang digunakan dalam Sistem ini menggunakan metodologi Rational Unified Process dengan tahapan berupa inception, elaboration, contruction dan transition. Dalam penelitian ini dapat dihasilkan sebuah sistem informasi geografis siap pakai dengan fitur utama yaitu laporan proges proyek dari mandor dan layanan keluhan masyarakat.
\end{abstract}

Kata Kunci - Geografis; Informasi; Monitoring; Sistem.

\section{PENDAHULUAN}

PT Sumber Berkat Indonesia adalah sebuah perusahaan terbatas yang bergerak dalam bidang pembangunan sebuah proyek hotel, yang sekarang ini sedang dalam proses yaitu pembangunan Hotel Amaris di TasikmalayaJawa barat. Dalam suatu proyek tentunya semua kegiatan saling berhubungan satu sama lain, saat ini banyak sekali faktor yang menjadi keterlambatan selain hanya faktor alam, diantaranya pemborong yang tidak bekerja yang sesuai dengan kesepakatan mengenai tenggat proyek yang telah ditentukan oleh pihak perusahaan. Selain itu bisa terjadinya kurang komunikasi atau bahkan administrasinnya itu sendiri belum sesuai.

Perusahaan yang menaungi proyek itu sendiri tentunya memiliki kendala dimana tidak bisa langsung memantau bagaimana progres pekerjaan itu berlangsung dari hari ke hari, kegiatan proyek harus dapat dikerjakan didalam kurun waktu yang telah ditentukan sebelum proyek itu sendiri dikerjakan, ini merupakan kegiatan sementara yang bekerja dalam jangka waktu yang sangat terbatas. Sebuah proyek itu berhasil ketika ketepatannya telah tercapai, yaitu tepat dalam biaya, tepat mutu dan tepat dalam waktu pengerjaan. Solusi dari permasalahan diatas yaitu perlu adanya sebuah sistem informasi tentunya dengan media teknologi dimana sebagai penghubung antara perusahaan dan pihak lapangan agar proyek dapat ter-monitoring dengan baik yaitu sistem informasi geografis monitoring data proyek yang berbasis web.

Sistem Informasi Geografis (SIG) merupakan suatu bahan yang berada di dalam hardware, software, serta berupa sebuah data geografis, dimana didalam sumber daya manusianya dapat bekerjasama secara efisien dan efektif untuk dapat menginputkan, save, repaired, update, mengelola, manipulating, integrated, menganalisis dan memperlihatkan data didalam suatu informasi yang berbasis data spasial geografis [1][2][3]. 
Beberapa jurnal penelitian sebelumnya yang membahas mengenai system ini, yang pertama pada penelitian aplikasi SIG untuk Monitoring Dan mengevaluasi data Proyek di Dinas Pekerjaan Umum Kota Kotamobagu [4], Yang kedua pada penelitian yang merancang bangun sebuah Sistem Informasi untuk Monitoring dalam perkembangan proyek yang berbasis Web (StudiKasus: PT. Inti Pratama Semesta) [5], Penelitian yang ketiga yaitu Sistem Informasi Geografis Sebaran Proyek [6], Dan yang keempat Perancangan Monitoring Absensi Dengan Fingerprint Berbasis Online [7], Dan yang kelima yaitu Sistem Informasi Geografis untuk memonitoring Alat dalam Apotek Kerja di PT Bayer Indonesia [8]. Gap analisis dalam perancangan yang akan dibuat ini akan menambahkan beberapa fitur lain yang mendukung proyek itu sendiri juga lebih memudahkan untuk dapat diakses berbagai pihak terkait.

Dengan demikian untuk mengendalikan kegiatan proyek, maka diperlukan suatu metode, disini penulis menggunakan metode Rational Unified Process (RUP) untuk menyelesaikan permasalahan diatas. RUP membagi proyek kedalam 4 fase, yakni Inception, Elaboration, Construction, dan Transition yang mengambil pendekatan step by step waterfall. Keunikannya ada pada iterasi yang terjadi pada setiap fasenya, ada beban kerja dan prosedur yang dilakukan masing-masing fase dengan porsi yang berbeda hingga proyek sepenuhnya rampung [9]. Berdasarkan yang melatar belakangi penelitian tersebut, penulis merancang bangun Sistem Informasi Geografis Monitoring Proyek Hotel Berbasis Web.

\section{URAIAN PENELITIAN}

Metodologi dalam penelitian Sistem Informasi Geografis (GIS) monitoring proyek hotel ini menggunakan Rational Unified Process (RUP) sebagai pemodelan perangkat lunak [10], dengan pemodelan Unified Modelling Language (UML) [11]. Metode ini dipilih karena mendukung dalam pembuatan sistem informasi geografis berbasis web, adapun tahapan-tahapannya yang digunakan akan dibahas pada bab ini.

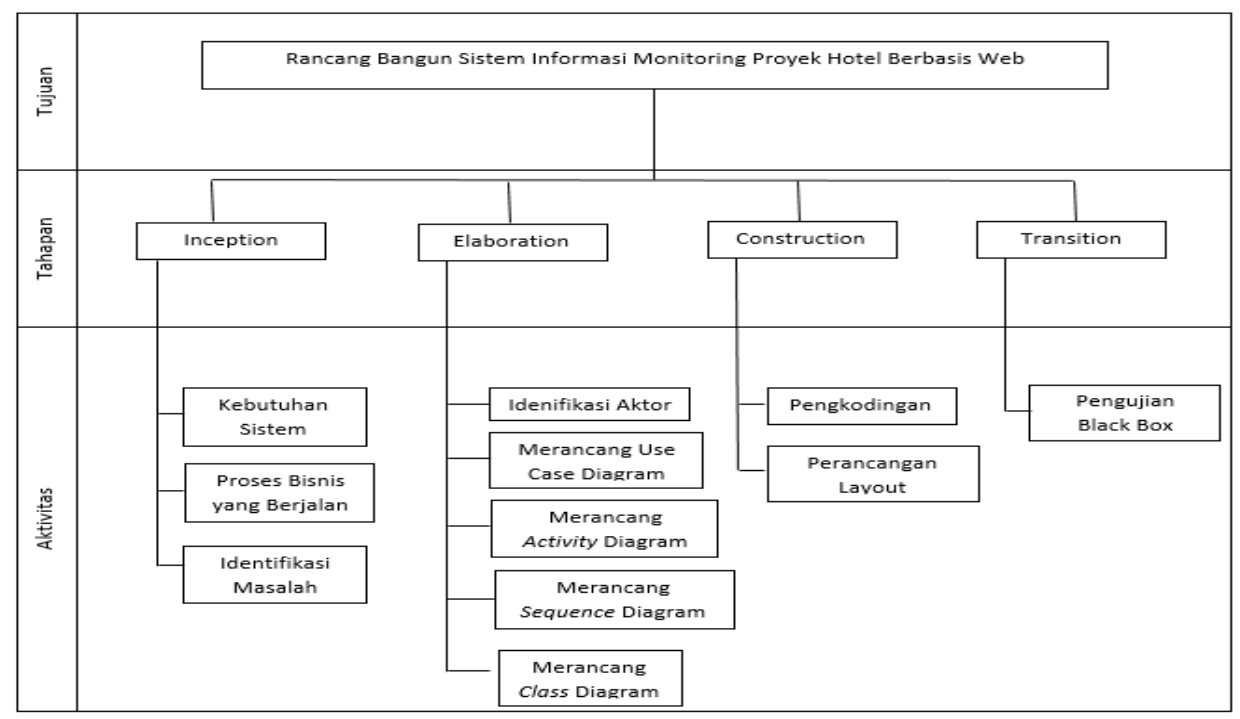

Gambar 1: Work Breakdown Structure

Dalam gambar I terdapat Work Breakdown Structure untuk metodologi penelitian terdiri dari empat tahapan yaitu:

1. Inception, Suatu tahapan dengan aktivitas kebutuhan system, proses bisnis yang sedang berjalan, identifikasi masalah

2. Elaboration, Suatu tahapan pada analisis dan desain system berdasarkan tahapn inception.

3. Construction, Mulai dari pengkodingan sampai perancangan layout dilakukan pada tahapan ini.

4. Transition, Tahapan dengan diadakan pengujian dengan menggunakan black box testing. 


\section{HASIL DAN PEMBAHASAN}

Dalam bagian ini menyajikan untuk keseluruhan hasil yang dilakukan dalam penelitian, dilakukan sesuai dengan tahapan rancangan perangkat lunak atau software yang digunakan dan mengenai pembahasan hasil dalam penelitian ini.

\section{A. Inception}

Pada aktivitas ini dilakukan pemodelan pada proses bisnis untuk menentukan kebutuhan sistem, berdasarkan studi literatur dan identifikasi masalah akan digambarkan melalui use case dan activity diagram pada tahap selanjutnya.

\section{Use Case Diagram}

Memaparkan hubungan diantara aktor dan sistem. Pada use case ini dapat diketahui siapa saja yang memiliki akses terhadap suatu fungsi [12].

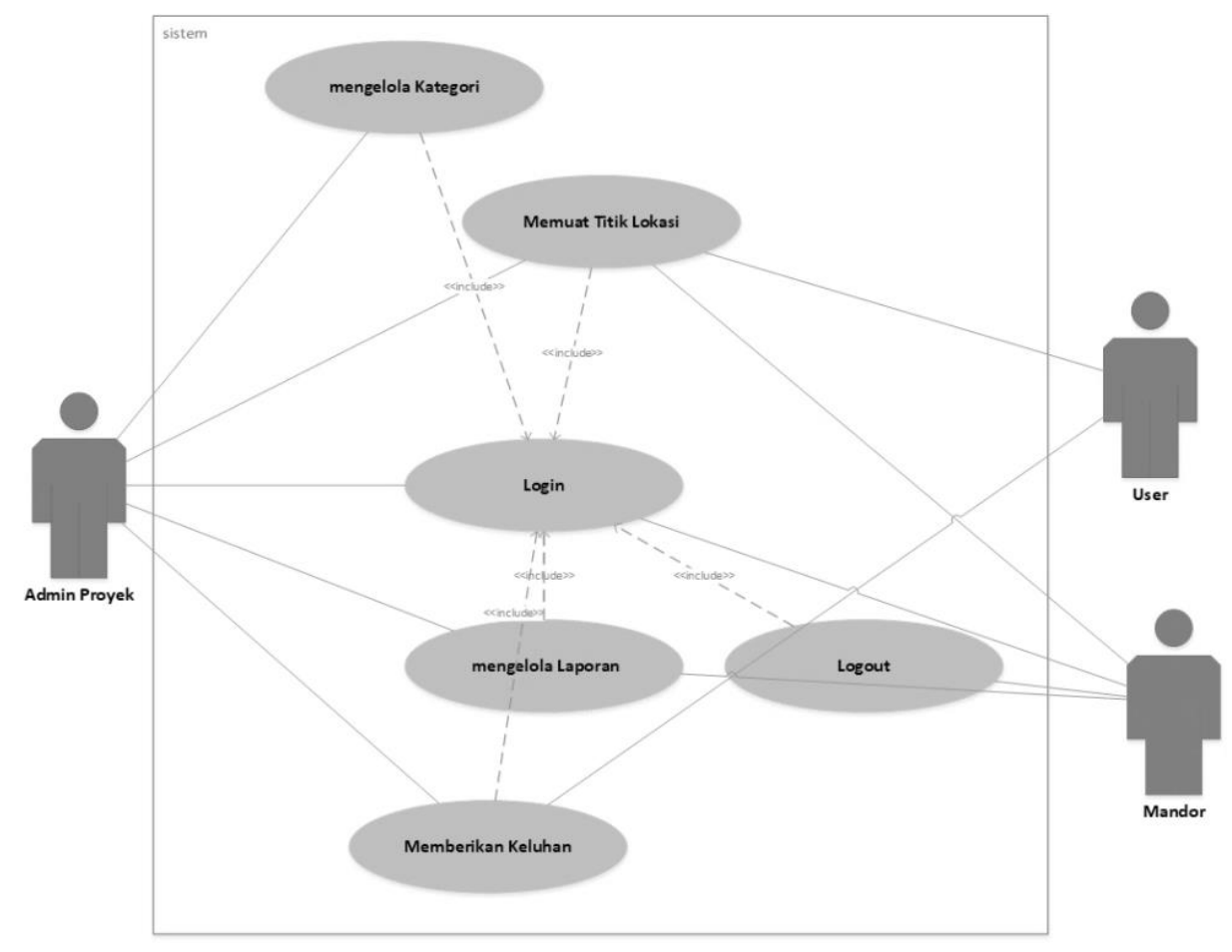

Gambar 2: Use Case Diagram

Pada Tabel 1, diperlihatkan aktor yang ada dalam proses aktivitas sistem informasi geografis monitoring proyek hotel berbasis web yang penjelasannya dapat dilihat pada Tabel 1.

Tabel 1: Identifikasi Aktor

\begin{tabular}{llll}
\hline No & Aktor & & \multicolumn{1}{c}{ Aktivitas } \\
\hline 1 & Admin & 1. & Mengelola kategori \\
& & 2. & Memuat Titik lokasi \\
& & 3. & Login \\
& & 4. & Mengelola laporan \\
& & 5. & Keluhan \\
\hline 2 & Mandor & 6. & Logout \\
\hline & & 1. & Mengelola laporan \\
& & 2. & Login
\end{tabular}




\begin{tabular}{llll}
\hline No & Aktor & \multicolumn{1}{c}{ Aktivitas } \\
\hline & & 3. & \multicolumn{1}{c}{ Logout } \\
& & 4. & Memuat Titik Lokasi \\
\hline 3 & User & 1. Memberikan Keluhan \\
& & 2. Memuat Titik Lokasi \\
\hline
\end{tabular}

\section{Activityy Diagram}

Berikut merupakan activity diagram mengelola kategori pada aplikasi Sistem Informasi Geografis Monitoring Proyek Hotel Berbasis Web.

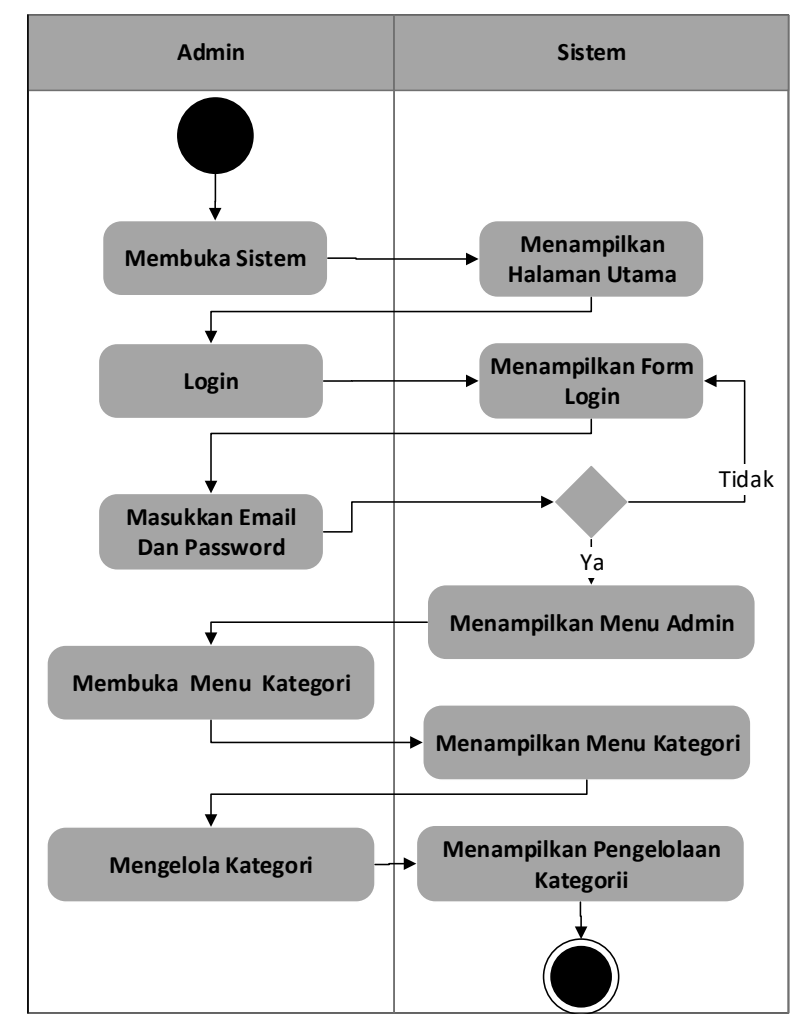

Gambar 3: Activity Diagram Mengelola Kategori

\section{B. Elaboration}

Pada fase elaborasi berfokus pada perancangan arsitektur system informasi geografis monitoring proyek yang memuat perancangan sistem dan rancangan antar muka.

1. Sequence Diagram

Perancangan Sequence Diagram, dimana menggambarkan interaksi antara pengguna dengan sistem, adapun rancangannya adalah sebagai berikut: 


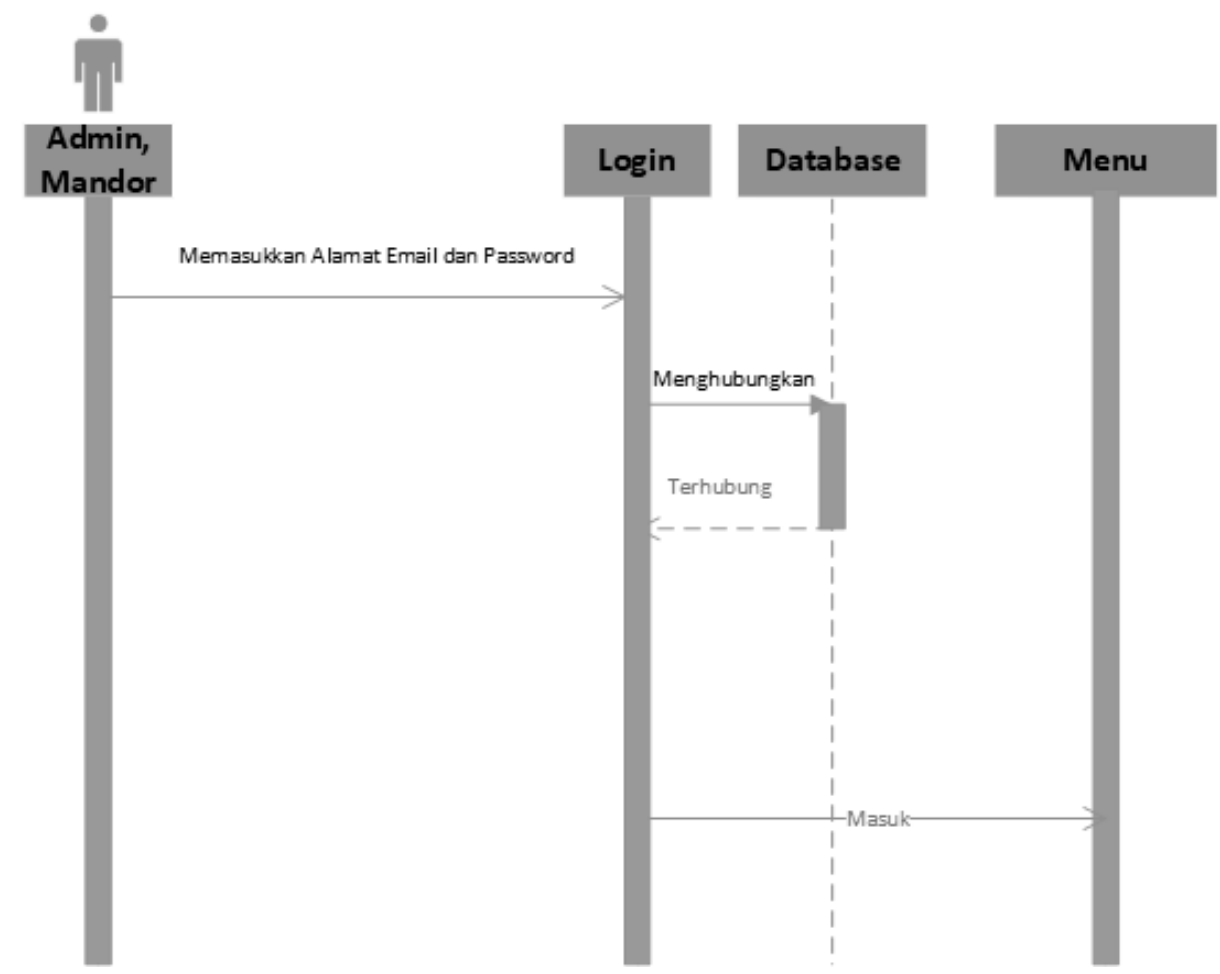

Gambar 0: Sequence Diagram Login

Pada Gambar 4. yang telah dipaparkan menjelaskan admin, mandor melakukan login dengan cara memasukkan akun, lalu sistem menghubungkan ke database untuk memeriksa akun apakah sesuai dengan simpanan data akun yang disimpan di dalam database.

\section{Class Diagram}

Perancangan Class Diagram ini dapat menggambarkan suatu struktur dan juga deskripsi serta menjelaskan bagaimana hubungan antar class diagram. 


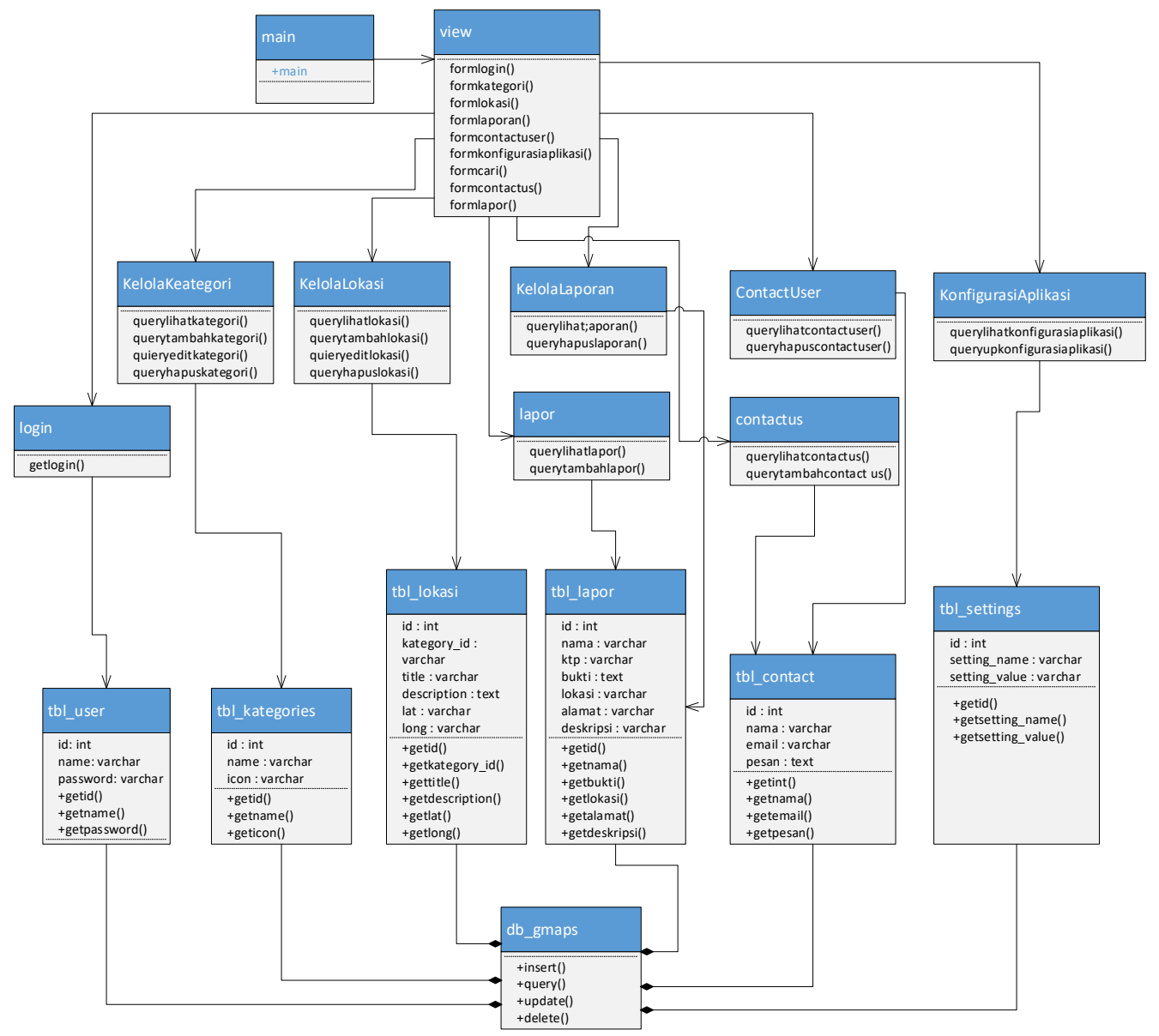

Gambar 5: Class Diagram

\section{Construction}

Pada tahap ini dilakukan implementasi dari perancangan user interface sistem infromasi geografis monitoring proyek, Menu Tampilan Awal Aplikasi pada Gambar 6 dan tampilan Login pada Gambar 7.

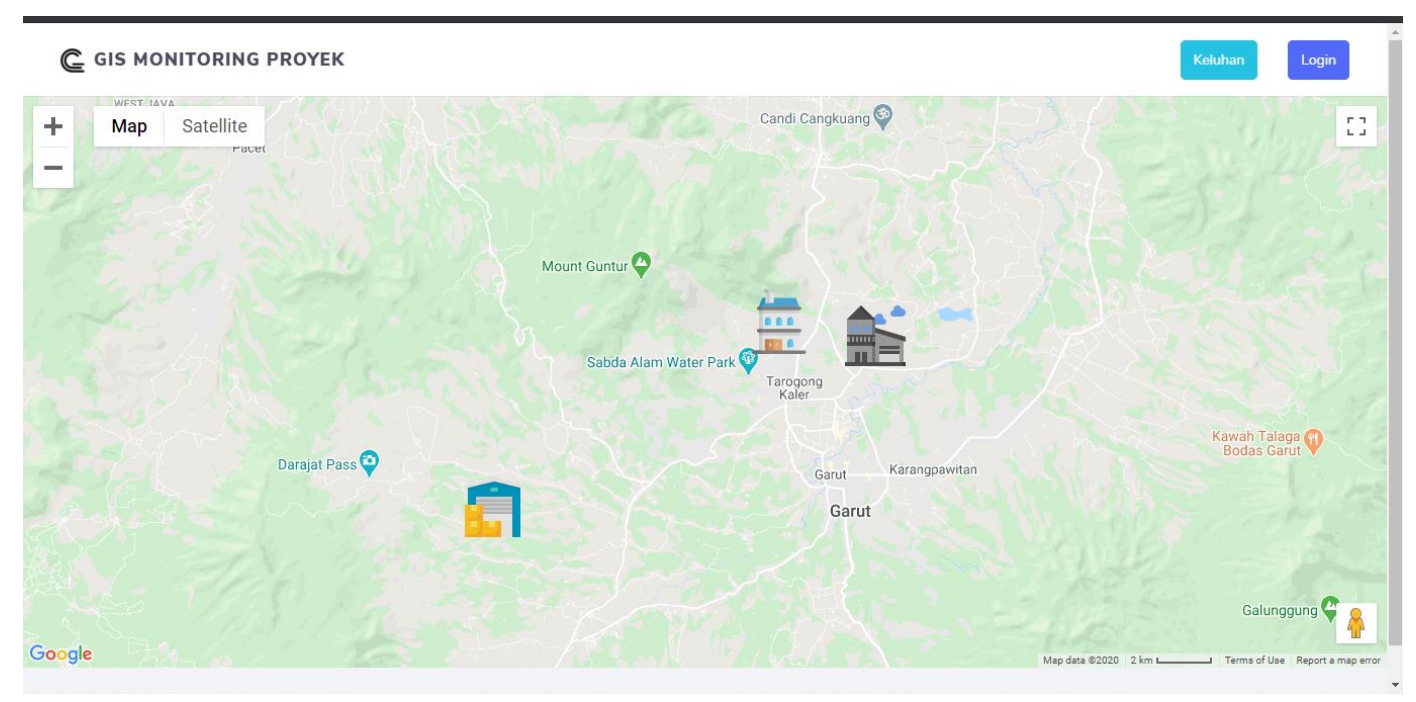

Gambar 6: Tampilan Awal Aplikasi 


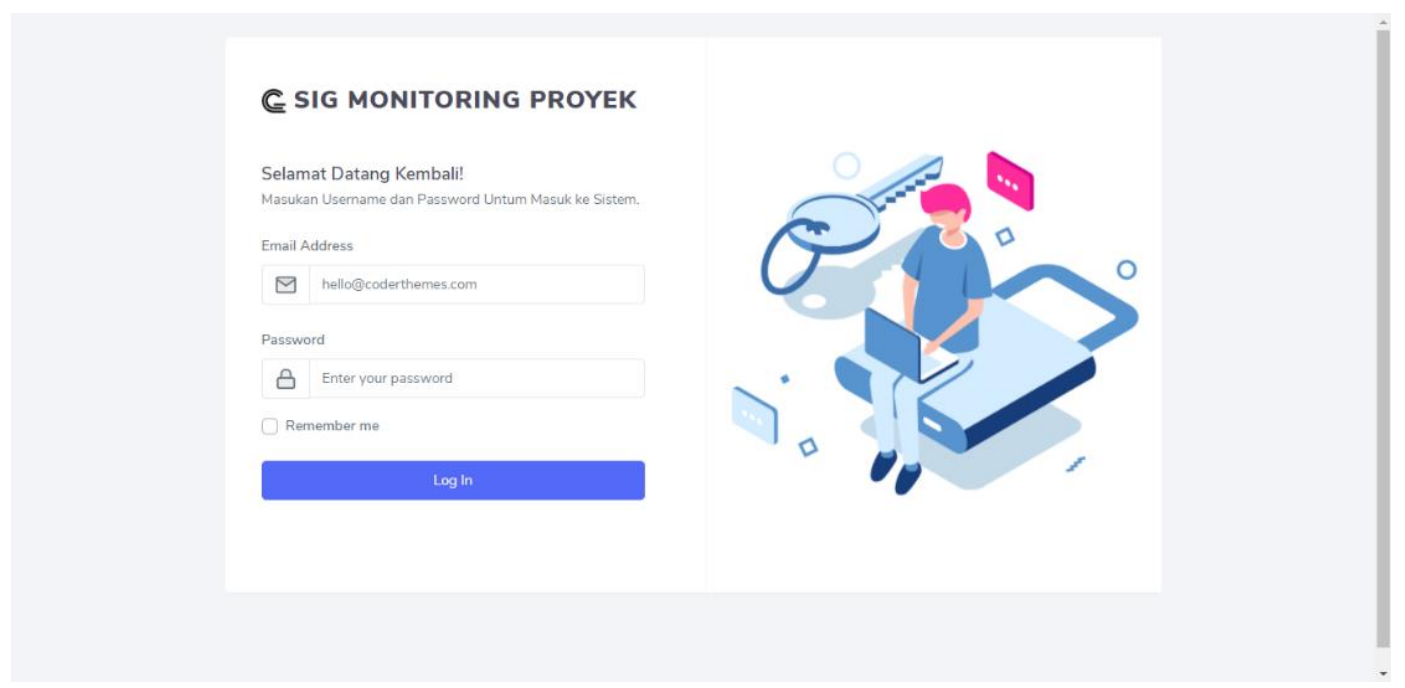

Gambar 7: Tampilan Login

\section{Transition}

Pada tahapan ini dilakukan pengujian dengan metode black box testing untuk menguji fungsionalitas fitur maupun menu pada aplikasi sistem infromasi geografis manajemen proyek. Berikut merupakan hasil dari pengujian blackbox testing:

Tabel 2 Hasil Pengujian Blackbox 0

\begin{tabular}{llll}
\multirow{2}{*}{ No } & \multicolumn{1}{c}{ Menu Atau Fitur } & \multicolumn{1}{c}{ Hasil } & \multicolumn{1}{c}{ Keterangan } \\
\cline { 3 - 4 } 1 & Halaman Umum & Tampil Halaman Umum & Error \\
\hline 2 & Login & $\begin{array}{l}\text { Berhasi login sesuai dengan hak } \\
\text { akses masing-masing }\end{array}$ & $\mathrm{V}$ \\
\hline 3 & Menginput Jenis Proyek & Kategori berhasil ditambahkan & $\mathrm{V}$ \\
\hline 4 & $\begin{array}{l}\text { Modifikasi data Jenis } \\
\text { Proyek }\end{array}$ & Data kategori berhasil dirubah & $\mathrm{V}$ \\
\hline 5 & $\begin{array}{l}\text { Menambah titik lokasi } \\
\text { Proyek }\end{array}$ & Data lokasi berhasil ditambahkan & $\mathrm{V}$ \\
\hline 6 & $\begin{array}{l}\text { Modifikasi data Titik } \\
\text { Lokasi Proyek }\end{array}$ & $\begin{array}{l}\text { Data titik lokasi berhasil } \\
\text { dimodifikasi }\end{array}$ & $\mathrm{V}$ \\
\hline 7 & $\begin{array}{l}\text { Menginput laporan } \\
\text { progress }\end{array}$ & Data laporan berhasil di input & $\mathrm{V}$ \\
\hline
\end{tabular}

\section{KESIMPULAN}

Diambil berdasarkan dari hasil dan pembahasan dalam penelitian yang dilakukan, dapat disimpulkan bahwa dalam merancang bangun sistem informasi geografis monitoring proyek hotel berbasis web adalah sistem menyajikan fitur yang diharapkan berguna untuk memudahkan pengguna dan perusahaan dalam melakukan pekerjaan monitoring agar semua bisa terkendali dengan baik dengan menggunakan metodologi Rational Unified Process (RUP) serta di dalam perancangan program menggunakan Bahasa pemrograman PHP. 


\section{DAFTAR PUSTAKA}

[1] A. Adil and S. Kom, Sistem Informasi Geografis. Penerbit Andi.

[2] L. Fitriani, S. Rahayu, D. Tresnawati, and A. D. Supriatna, "Geographical information system of fire incidents data monitoring," J. Phys. Conf. Ser., vol. 1402, no. 6, p. 066101, 2019, doi: 10.1088/17426596/1402/6/066101.

[3] L. Fitriani and T. Faturochman, "Rancang Bangun Sistem Informasi Geografis Pariwisata Dan Industri Berbasis Web," algoritma, vol. 15, no. 2, 2018, Accessed: Jan. 29, 2019. [Online]. Available: http://journal.sttgarut.ac.id/index.php/algoritma/article/view/133.

[4] D. H. Makalalag, Y. D. Y. Rindengan, and R. Sengkey, "Sistem Informasi Geografis Monitoring Dan Evaluasi Proyek Dinas Pekerjaan Umum Kota Kotamobagu," J. Tek. Inform., vol. 9, no. 1, 2016.

[5] A. Aprisa and S. Monalisa, "Rancang bangun sistem informasi monitoring perkembangan proyek berbasis web (studi kasus: Pt. inti pratama semesta)," J. Ilm. Rekayasa dan Manaj. Sist. Inf., vol. 1, no. 1, pp. 49-54, 2015.

[6] S. Hidayat, "Sistem Informasi Geografis Sebaran Proyek," in GLOBAL, 2018, vol. 5, no. 2.

[7] M. Rois Dien and L. Fitriani, "Perancangan Monitoring Absensi Dengan Fingerprint Berbasis Online," 2017. Accessed: Jan. 08, 2020. [Online]. Available: http://journals.sttgarut.ac.id.

[8] R. Arismunandar, "Sistem Informasi Geografis Sebagai Alat Monitoring Terhadap Apotek Kerja Sama PT Bayer Indonesia," J. Nas. Teknol. dan Sist. Inf., vol. 3, no. 1, pp. 187-198, 2017.

[9] F. Sulianta, "Strategi Merancang Arsitektur Sistem Informasi Masa Kini." Jakarta. PT Elex Media Komputindo, 2019.

[10] O. Novitasari, "Implementasi Rational Unified Process Pada Sistem Informasi Simpan Pinjam Kelompok Perempuan." CITISEE, 2017.

[11] B. Ali, "Object Oriented System Development using the Unified Modeling Language." Boston. McGraw-Hill, 1999.

[12] K. Bittner and I. Spence, Use case modeling. Addison-Wesley Professional, 2003. 